\title{
TCF 7L2 rs7903146 impairs islet function and morphology in non-diabetic individuals
}

\author{
O. Le Bacquer • J. Kerr-Conte • S. Gargani • \\ N. Delalleau • M. Huyvaert • V. Gmyr • P. Froguel • \\ B. Neve $\cdot$ F. Pattou
}

Received: 2 April 2012 / Accepted: 15 June 2012 /Published online: 22 August 2012

(C) Springer-Verlag 2012

\begin{abstract}
Aims/hypothesis Transcription factor 7-like 2 (TCF7L2) is a Wnt-signalling-associated transcription factor. Genetic studies have clearly demonstrated that DNA polymorphisms within TCF7L2 confer the strongest known association with increased risk of type 2 diabetes. However, the impact of the TCF7L2 type-2-diabetes-associated rs7903146 T allele on biological function and morphology of human pancreatic islets is unknown.

Methods Paraffin sections of pancreases from 187 braindeceased donors $\left(\mathrm{HbA}_{1 \mathrm{c}}<6.5 \%\right.$ [ $\left.\left.48 \mathrm{mmol} / \mathrm{mol}\right]\right)$ were used
\end{abstract}

Electronic supplementary material The online version of this article (doi:10.1007/s00125-012-2660-8) contains peer-reviewed but unedited supplementary material, which is available to authorised users.

O. Le Bacquer $\cdot$ J. Kerr-Conte $\cdot$ S. Gargani $\cdot$ N. Delalleau $\cdot$

M. Huyvaert $\cdot$ V. Gmyr $\cdot$ P. Froguel $\cdot$ B. Neve $\cdot$ F. Pattou

Université Lille Nord de France,

Lille, France

O. Le Bacquer $\cdot$ J. Kerr-Conte $(\bowtie) \cdot S$. Gargani $\cdot$ N. Delalleau $\cdot$

V. Gmyr $\cdot$ F. Pattou

Faculty of Medicine, Inserm UMR859, Biotherapies for Diabetes,

1 Place de Verdun,

59000 Lille, France

e-mail: jkerr-conte@univ-lille2.fr

O. Le Bacquer $\cdot$ M. Huyvaert $\cdot$ P. Froguel $\cdot$ B. Neve $(\bowtie)$

CNRS UMR 8199, Institut de Biologie de Lille,

1 Rue du Professeur Calmette,

59021 Lille Cedex, France

e-mail: Bernadette.neve@good.ibl.fr

P. Froguel

Imperial College London,

London, UK

F. Pattou

Department of Endocrine Surgery,

Centre Hospitalier Universitaire de Lille,

Lille, France to genotype the TCF7L2 variant rs7903146 and evaluate its impact on islet morphology and alpha and beta cell subpopulations following immunostaining for glucagon and Cpeptide. Following islet isolation, we investigated the correlation between $T C F 7 L 2$ genotype and in vitro islet functional variables from our in-house pancreatic database.

Results TCF7L2 rs7903146 (T/T) was associated with reduced basal and glucose-stimulated insulin secretion in isolated human islets, and reduced islet density in whole pancreas. Morphological analysis demonstrated islet size was increased in T/T carriers. Furthermore, rs7903146 was associated with an increased glucagon/C-peptide ratio, especially in bigger islets.

Conclusion/interpretation The TCF7L2 variant rs7903146 risk allele is associated with impaired insulin secretion, reduction of total islet number and quantitative as well as qualitative morphological changes in human islets. Understanding how the TCF7L2 genotype modulates its activity and how TCF7L2 impacts the islet morphology may aid the design of new therapeutic approaches for the treatment of type 2 diabetes.

Keywords Human islet · Morphological analysis ·

Polymorphism $\cdot$ TCF 72

$\begin{array}{ll}\text { Abbreviations } \\ \text { GLP-1 } & \text { Glucagon-like peptide-1 } \\ \text { IE } & \text { Islet equivalent } \\ \text { SNP } & \text { Single-nucleotide polymorphism } \\ \text { TCF7L2 } & \text { Transcription factor 7-like 2 }\end{array}$

\section{Introduction}

To date, intronic variants associated with TCF7L2 (singlenucleotide polymorphisms [SNPs] rs7903146 and rs12255375) confer the highest genetic risk of developing 
type 2 diabetes [1]. Although biological studies clearly demonstrate the role of transcription factor 7-like 2 (TCF7L2) on insulin secretion and the survival of isolated islets $[2,3]$, the effect of the TCF $2 L 2$ risk allele on islet functions and pancreatic morphology in humans remains poorly documented. A recent study using human islet preparations demonstrated the potential of elucidating the effect of genetic variants on insulin exocytosis [4]. Herein, we took advantage of our clinical/research in-house islet database and collection of archived paraffin-embedded pancreases from healthy non-diabetic human organ donors [5] to study the effect of TCF7L2 rs7903146 on isolated islet functions and pancreatic morphology. Retrospective genotyping of donors was possible from paraffin-embedded samples when cells were no longer available.

\section{Methods}

Islet evaluation Pancreases were harvested from human brain-deceased donors and processed as described in the electronic supplementary material (ESM) for islet isolation. After culture for 18-36 h, the quality of human islets was checked as previously described [5]. Assessment included islet counting using dithizone and Trypan Blue (in triplicate), and insulin content of cell lysates (40 IE (islet equivalent) in triplicate) with a radioimmunoassay kit (CIS Bio International, Saclay, France). Glucose-stimulated insulin secretion was determined by static incubations $(1 \mathrm{~h}$ : $2.8 \mathrm{mmol} / 1$ glucose; $1 \mathrm{~h} 20 \mathrm{mmol} / 1$ glucose; five aliquots of $40 \mathrm{IE})$. Stimulation indices are defined as the ratio of stimulated ( $20 \mathrm{mmol} / \mathrm{l}$ glucose) to basal $(2.8 \mathrm{mmol} / \mathrm{l}$ glucose $)$ insulin release. Secreted insulin was also corrected to intracellular insulin and insulin secretion expressed as a percentage of the total insulin content in 40 IE.

Morphometric analysis For endocrine mass assessment, sections were immunolabelled with chromogranin A primary antibody (Dako, Trappes, France; Clone M0869) and revealed with Envision ${ }^{\mathrm{M}}+$ system (Dako, K4003) using Phtalored (Histomark, Kirkegaard \& Perry Laboratories, Gaithersburg, MD, USA). All washes were performed with $0.05 \mathrm{~mol} / 1$ Tris-HCl, $0.15 \mathrm{~mol} / \mathrm{l} \mathrm{NaCl}(\mathrm{pH}$ 7.6). Nuclei were counterstained with Carazzi's haematoxylin. Slides were scanned with a Nikon Eclipse Ti microscope, and the fractional area was digitally quantified (Nis Elements AR 3.0) (Nikon, Champigny sur Marne, France). The percentage of endocrine mass was calculated as the ratio of the chromogranin-A-positive surface area to the total tissue surface area. Similarly, beta and alpha cell surface areas were determined using Alexa-488-conjugated anti-human C-peptide (green) (Monosan, Uden, the Netherlands; MON5021) or anti-glucagon (SIGMA, St-Quentin Fallavier, France) using Lightning-Link conjugation kit (Innova Biosciences, Cambridge, UK); nuclei were stained with DAPI (blue) (Vector Laboratories, Burlingame, CA, USA; H1200J). A Leica DM-R microscope (Leica, Nanterre, France) and ImageJ (NIH, Bethesda, MD, USA) were used for the quantitative analysis of alpha and beta cells vs total endocrine cell surface.

The complete methods for islet isolation, DNA extraction from pancreatic paraffin sections and TCF7L2 rs7903146 SNP genotyping, isolated islet in vitro evaluation, real-time quantitative PCR, histological and morphometric analyses and quantification of islets are described in the ESM.

\section{Results}

Descriptive study exploiting the human islet database To study the effect of TCF7L2 genetic variants on pancreatic function, we genotyped rs7903146 from 187 donors. We used sections of archived pancreatic tissue in paraffin blocks and a database with corresponding information on the clinical donor, islet isolation and in vitro islet functional variables. Of the donors, 57 were heterozygous and 21 homozygous for the at-risk TCF $7 L 2 \mathrm{~T}$ allele. There were no differences in age, $\mathrm{BMI}$ or $\mathrm{HbA}_{1 \mathrm{c}}$ levels between donors

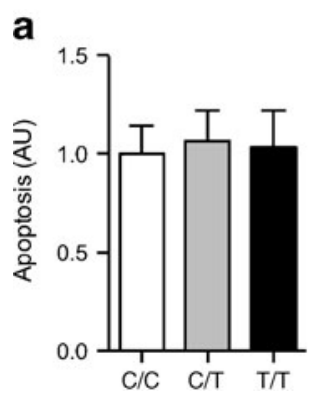

Fig. 1 TCF7L2 variant rs7903146 alters insulin secretion of isolated human islets. (a) Islet apoptosis measured after an overnight culture. (b) Insulin secretion of cultured islets was measured in the presence of $2.8 \mathrm{mmol} / \mathrm{l}$ glucose (basal, white bars) or $20 \mathrm{mmol} / 1$ glucose
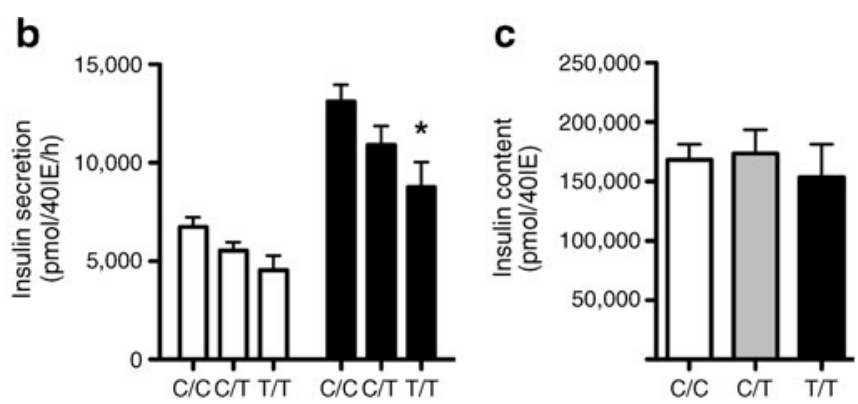

(stimulated, black bars). (c) Islet insulin content. Insulin content was determined in the lysate of six aliquots of 40 IE. Values are means \pm SEM from $109 \mathrm{C} / \mathrm{C}, 57 \mathrm{C} / \mathrm{T}$ and $21 \mathrm{~T} / \mathrm{T}$ donors. ${ }^{*} p<0.05$ vs $\mathrm{C} / \mathrm{C}$ 
(ESM Table 1). First, we measured TCF7L2 expression in isolated pancreatic islets from 26 human donors for whom mRNA was available $(11 \mathrm{C} / \mathrm{C}$, nine $\mathrm{C} / \mathrm{T}$ and six $\mathrm{T} / \mathrm{T})$. As previously observed [6], TCF7L2 expression was increased twofold in T/T carriers. The expression of insulin and glucagon was unaltered by genotype (ESM Fig. $1, p<0.05$ ). In addition, islet viability in culture was unaffected by the TCF7L2 genotype (Fig. 1a). In vitro insulin secretion in islets from $\mathrm{T} / \mathrm{T}$ donors was reduced $30 \%$ both under basal conditions $(p=0.08)$ and after glucose stimulation $(p<0.05)$ compared with $\mathrm{C} / \mathrm{C}$ islet donors (Fig. 1b). In contrast, the intracellular insulin content (Fig. 1c) and stimulatory index were unaltered by TCF7L2 genotype $(2.18 \pm 0.14,1.94 \pm$ 0.12 , and $1.82 \pm 0.28$, respectively, for $\mathrm{C} / \mathrm{C}, \mathrm{C} / \mathrm{T}$ and $\mathrm{T} / \mathrm{T}$ genotype).

Analysis of pancreas tissue The total mass of pancreatic tissue (the ratio of chromogranin-A-positive surface area to total tissue area) was not altered in pancreatic sections from $\mathrm{C} / \mathrm{T}$ or $\mathrm{T} / \mathrm{T}$ donors compared with $\mathrm{C} / \mathrm{C}$ donors (Figs $2 \mathrm{a}$ and ESM Fig. 2). However, islet count after enzymatic digestion of the pancreas showed an approximately $30 \%$ reduction in pancreases with $\mathrm{T} / \mathrm{T}$ compared with $\mathrm{C} / \mathrm{C}$ donors (ESM Fig. 3, $p<0.05$ ). We observed that islets of $\mathrm{T} / \mathrm{T}$ genotype donors tended to be larger compared with $\mathrm{C} / \mathrm{C}$ or $\mathrm{C} / \mathrm{T}$ donors, with a lower number of islets with a diameter $<100 \mu \mathrm{m}(p<0.05)$ and a higher number with a diameter $100-250 \mu \mathrm{m}(p<0.05)$ (ESM Fig. 3). We also noticed a trend towards larger islets (with a diameter $>250 \mu \mathrm{m}$, ESM Fig. 3) in $\mathrm{T} / \mathrm{T}$ donors.

Islet morphology analysis on paraffin sections To determine if TCF7L2 genetic variants have different islet morphology, we double-immunolabelled pancreatic sections for Cpeptide (beta cells) and glucagon (alpha cells). For each cell type the surface was quantified and expressed as a percentage of total islet surface. We observed an approximately $30 \%$ increase in the alpha cell surface in $\mathrm{T} / \mathrm{T}$ islets compared with $\mathrm{C} / \mathrm{C}$ islets $(18.7 .0 \pm 0.5 \%$ vs $24.3 \pm 0.7 \%$, respectively, in $\mathrm{C} / \mathrm{C}$ and $\mathrm{T} / \mathrm{T}$ islets, Figs $2 \mathrm{~b}$ and ESM Fig. 2, $p<0.01$ ). On the other hand, the beta cell surface was reduced by approximately $20 \%$ in $\mathrm{T} / \mathrm{T}$ islets $(49.7 \pm 0.6 \%$ vs $40.6 \pm 0.8 \%$, Figs $2 \mathrm{~b}$ and ESM Fig. $2, p<0.01)$. This imbalance between alpha and beta cells leads to an increased alpha/beta ratio from $0.55 \pm 0.03$ to $0.85 \pm 0.07$ in $\mathrm{T} / \mathrm{T}$ islets compared with $\mathrm{C} / \mathrm{C}$ islets (Fig. 2c, $p<0.001$ ). As TCF7L2 rs7903146 impacts islet size, we stratified islets by their size and looked at the alpha/beta cell ratio in the different subpopulations. TCF7L2 genotype did not significantly change the alpha/ beta cell ratio in small islets (size $<15,000 \mu \mathrm{m}^{2}$ ). Regardless of islet size, no modification of the alpha/beta cell ratio was observed in the heterozygous $\mathrm{C} / \mathrm{T}$ islets. However, in $\mathrm{T} / \mathrm{T}$ islets, the alpha/beta cell ratio was increased 2.8 -fold in a

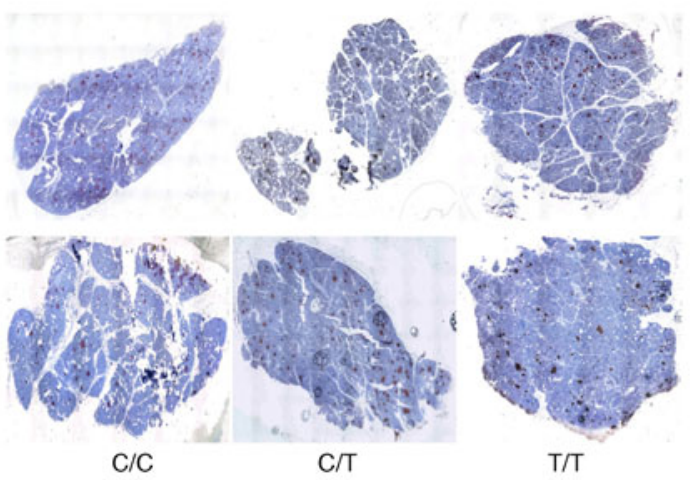

b

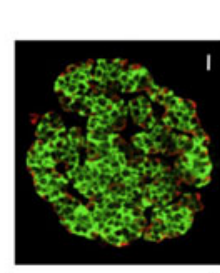

Glucagon/C-peptide
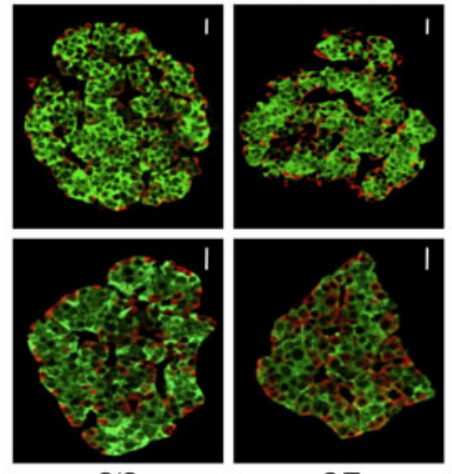

$\mathrm{C} / \mathrm{T}$

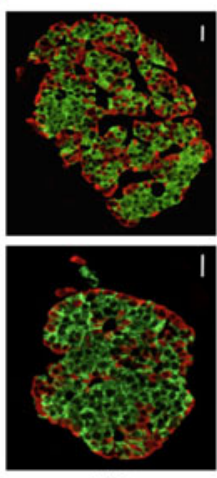

$\mathrm{T} / \mathrm{T}$

C

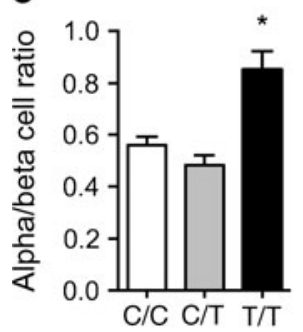

d

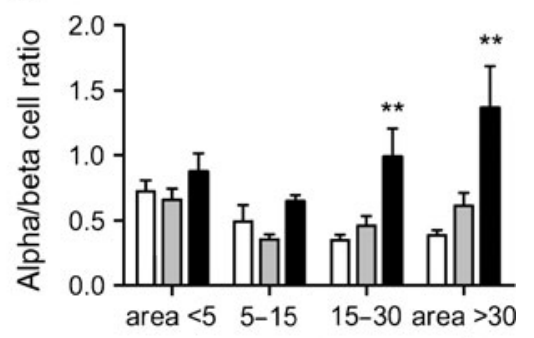

Islet surface $\left(x 1,000 \mu \mathrm{m}^{2}\right)$

Fig. 2 TCF7L2 variant rs7903146 alters islet morphology. (a) Endocrine surface of human pancreatic sections after immunolabelling for anti-chromogranin A. Two representative sections per genotype are shown (magnification $\times 40$ ). (b) Alpha and beta cell immunofluorescence. Pancreatic sections were stained for C-peptide (green) and glucagon (red). Representative islets are shown (scale bar $25 \mu \mathrm{m}$, magnification $\times 300$ ). (c) Alpha/beta cell ratio in human islets. The relative area of immunofluorescence was quantified and used to calculate the alpha/beta cell ratio for each islet. (d) Alpha/beta cell ratio in islet subpopulations. White bars, C/C; grey bars, C/T; black bars, T/T. ${ }^{*} p<$ $0.05,{ }^{* *} p<0.001$ vs $\mathrm{C} / \mathrm{C}$

$15,000-30,000 \mu \mathrm{m}^{2}$ islets $(p<0.01)$ and 3.5 -fold in islets $>30,000 \mu \mathrm{m}^{2}$ (Fig. $2 \mathrm{~d}, p<0.01$ ).

\section{Discussion}

In line with large cohort studies showing that the rs7903146 risk allele is associated with hyperglycaemia, lower fasting 
insulin level and decreased beta cell function in vivo, a recent study reported that carriers of the of TCF $7 L 2$ rs7903146 risk allele have reduced insulin secretion compared with those with the non-risk allele [4]. In the present study we confirmed this result and observed that the 'at-risk' allele of TCF7L2 rs7903146 was associated with morphological and functional differences. Pancreases from donors carrying homozygous 'at-risk' alleles (T/T) have: (1) reduced glucose-induced insulin secretion; and (2) altered endocrine tissue as exemplified by increased individual islet size and altered alpha and beta cell ratio/distribution within islets.

In islets from non-diabetic $\mathrm{T} / \mathrm{T}$ donors, the relative alpha cell population is increased compared with $\mathrm{C} / \mathrm{C}$ donors, whereas the relative beta cell population is reduced, which results in an increased alpha/beta ratio. Such alterations in alpha and beta cell populations were previously observed in mice after streptozotocin (STZ)-induced diabetes [7] and in diabetic patients [8]. Interestingly, the alpha/beta cell ratio is increased in type 2 diabetes compared with controls and this alteration is predominantly observed in larger islets [8]. Furthermore, a recent study observed an increased expression of TCF7L2 mRNA in FACS-sorted alpha cells compared with sorted beta cells [9]. This suggests that TCF7L2 variant rs7903146 delineates, at least at the morphological level, a state of diabetes, and that increased TCF7L2 expression might be associated with alpha cell development.

It is well known that changes in beta cell mass can occur in response to physiological and/or pathological conditions [10]. To our knowledge, only one study has investigated the role of the Wnt/TCF7L2 pathway in the in vivo regulation of beta cell growth. TCF7L2 knockdown in rat islets results in a 30\% reduction of the beta cell mass and impaired beta cell regeneration after STZ treatment [11]. The authors suggest that normal and compensatory growth of beta cells in their model was mainly mediated by the inhibition of beta cell proliferation. An expansion of alpha cell mass was observed in diabetic humans [8]. Such alpha cell expansion also occurs in the development of diabetes in mice subjected to STZ treatment and is associated with reduced beta cell mass [7]. In STZ-treated mice, inhibition of dipeptidyl peptidase-4 (the glucagon-like peptide 1 [GLP-1] degrading enzyme) protects islet morphology by preventing beta cell apoptosis and inhibiting STZ-induced alpha cell proliferation [7]. GLP-1 secretion is not affected by the TCF7L2 genotype after a glucose oral test or meal [12]. However, TCF7L2 variant rs 7903146 modulates the incretin action, as GLP-1 infusion combined with hyperglycaemic clamp showed a significant reduction in GLP-1-induced insulin secretion in the carriers of the TCF7L2 risk allele [12].
Furthermore, reduced $T C F 7 L 2$ expression occurs in type 2 diabetes animal models [3], and TCF7L2 deletion leads to reduced GLP-1 receptor expression in isolated human islets [3]. TCF7L2 mRNA expression is increased in human islets from patients with type 2 diabetes and in islets from carriers of the T/T genotype [6], in contrast with the effect of $T C F 7 L 2$ deletion on GLP-1 receptor expression. However, our recent study demonstrated that different TCF7L2 transcripts have different effects on islet survival and functions, including GLP-1 receptor expression [2]. Whether the TCF7L2 variant rs7903146 is modulating alpha cell expansion and beta cell loss through its effect on incretin signalling will require further investigation.

In summary, by genotyping archived pancreatic paraffin sections and the retrospective analysis of a clinical islet database, we show for the first time the impact of the TCF7L2 variant rs7903146 on the functions and the morphological organisation of the pancreatic islets in nondiabetic humans, which may explain in part its contribution to type 2 diabetes physiology.

Acknowledgements The authors are indebted to R. Verhaeghe, R. Ezzouaoui, L. Arnalsteen, A. Sterkers, C. Chevalier and the local coordination team of the French organ procurement agency (Agence de la Biomédecine) for pancreas procurement. Special thanks to $\mathrm{M}$. Marchand and S. Vivequin for technical assistance, and to J. Thevenet, I. Aluka, S. Belaich and E. Moerman for islet isolation and evaluation. The authors thank A. Abderrahmani and B. Lefebvre for helpful comments on the manuscript.

Funding This work was supported in part by grants from Conseil Régional Nord Pas de Calais (European Genomics Institute of Diabetes [EGID]), Contrat Plan Etat Région Cardio Diabète (CPER), including OLB's postdoctoral fellowship, Agence Nationale de la Recherche (ANR-10-LABX-46, ANR-10-EQPX-07-01, ANRBlanc), Fonds Européen de Développement Régional (FEDER), Agence de la Biomédecine, INSERM, European Consortium for Islet Transplantation funded by Juvenile Diabetes Research Foundation International, and core facilities including the Biotherapies Platform provided by or funded by IFR 114 Institut de Médecine Prédictive et de Recherche Thérapeutique, and the University Hospital of Lille.

Contribution statement The following authors conceived and designed the experiments: OLB, PF, FP, JK-C and BN. Paraffinembedded pancreatic sections were genotyped by: OLB, BN and MH. OLB, JKC and BN wrote the paper. OLB, JK-C, MH, ND, VG and $\mathrm{BN}$ analysed the data. The immunostaining of human islets was performed by SG, ND and VG. OLB and SG undertook the islet morphometric analysis. OLB, JKC, SG, ND, MH, VG, PF, BN and FP were involved in the draft and critically revised this manuscript for intellectual content. BN and JK-C supervised the project. All the authors approved the final version of this manuscript.

Duality of interest The authors declare that there is no duality of interest associated with this manuscript. 


\section{References}

1. Schafer SA, Machicao F, Fritsche A, Haring HU, Kantartzis K (2011) New type 2 diabetes risk genes provide new insights in insulin secretion mechanisms. Diabetes Res Clin Pract 93(Suppl 1):S9-S24

2. Le Bacquer O, Shu L, Marchand M et al (2011) TCF7L2 splice variants have distinct effects on beta cell turnover and function. Hum Mol Genet 20:1906-1915

3. Shu L, Matveyenko AV, Kerr-Conte J, Cho JH, McIntosh $\mathrm{CH}$, Maedler K (2009) Decreased TCF7L2 protein levels in type 2 diabetes mellitus correlate with downregulation of GIP- and GLP-1 receptors and impaired beta cell function. Hum Mol Genet 18:2388-2399

4. Rosengren AH, Braun M, Mahdi T et al (2012) Reduced insulin exocytosis in human pancreatic beta cells with gene variants linked to type 2 diabetes. Diabetes 61:1726-1733

5. Vantyghem MC, Kerr-Conte J, Arnalsteen L et al (2009) Primary graft function, metabolic control, and graft survival after islet transplantation. Diabetes Care 32:1473-1478

6. Lyssenko V, Lupi R, Marchetti P et al (2007) Mechanisms by which common variants in the TCF7L2 gene increase risk of type 2 diabetes. J Clin Invest 117:2155-2163
7. Takeda Y, Fujita Y, Honjo J et al (2012) Reduction of both beta cell death and alpha cell proliferation by dipeptidyl peptidase- 4 inhibition in a streptozotocin-induced model of diabetes in mice. Diabetologia 55:404-412

8. Yoon KH, Ko SH, Cho JH et al (2003) Selective beta cell loss and alpha cell expansion in patients with type 2 diabetes mellitus in Korea. J Clin Endocrinol Metab 88:2300-2308

9. Kirkpatrick CL, Marchetti P, Purrello F et al (2010) Type 2 diabetes susceptibility gene expression in normal or diabetic sorted human alpha and beta cells: correlations with age or BMI of islet donors. PLoS One 5:e11053

10. Ackermann AM, Gannon M (2007) Molecular regulation of pancreatic beta cell mass development, maintenance, and expansion. $\mathrm{J}$ Mol Endocrinol 38:193-206

11. Figeac F, Uzan B, Faro M, Chelali N, Portha B, Movassat J (2010) Neonatal growth and regeneration of beta cells are regulated by the Wnt/beta-catenin signaling in normal and diabetic rats. Am J Physiol Endocrinol Metab 298:E245E256

12. Schafer SA, Tschritter O, Machicao F et al (2007) Impaired glucagon-like peptide-1-induced insulin secretion in carriers of transcription factor 7-like 2 (TCF7L2) gene polymorphisms. Diabetologia 50:2443-2450 